Article

\title{
Spreading the Eco-Message: Using Proactive Coping to Aid Eco-Rep Behavior Change Programming
}

\section{Brittany Bloodhart $^{1}{ }^{1}$, Janet K. Swim ${ }^{2}$ and Matthew J. Zawadzki ${ }^{3}$}

1 Center for Climate Change Communication, George Mason University, 4400 University Drive, Fairfax, VA 22030, USA

2 Department of Psychology, The Pennsylvania State University, Department of Psychology, 251 Moore Bldg., University Park, PA 16802, USA; E-Mail: jks4@ psu.edu

3 Department of Biobehavioral Health, The Pennsylvania State University, 219 Biobehavioral Health Bldg., University Park, PA 16802, USA; E-Mail: mjz172@psu.edu

* Author to whom correspondence should be addressed; E-Mail: brittanybloodhart@ gmail.com; Tel.: +1-703-993-8368.

Received: 6 March 2013; in revised form: 30 March 2013 / Accepted: 7 April 2013 /

Published: 18 April 2013

\begin{abstract}
Making pro-environmental behavior changes can be difficult, particularly when these changes challenge daily routines and comfortable lifestyles. We designed and implemented an eco-representative intervention program to help students reduce their energy use by proactively coping with barriers to pro-environmental behavior change, and then communicate effective behavior change strategies to student peers. Twenty-nine first-year college students participated in a four-week proactive coping training to change five environmentally impactful behaviors and then spread behavior change messages to fellow residents during a two-week energy challenge. Eco-reps successfully changed their own behaviors in a pro-environmental direction by generating important barriers and successful facilitators for behavior change, and eco-rep residence halls were more likely to reduce energy and maintain reductions compared to non-eco-rep halls. Implications for future environmental behavior change interventions are discussed.
\end{abstract}

Keywords: eco-teams; proactive coping; pro-environmental behavior change; student intervention programs; residence hall competition 


\section{Introduction}

Changing one's lifestyle to be more sustainable can be difficult, particularly when energy-consuming behaviors become automatic and habitual (e.g., taking long showers or taking elevators rather than stairs). Even those who care strongly about nature often do not engage in pro-environmental behavior, an effect that has become known as the value-action gap [1]. College students living in residence halls represent an important and potentially receptive population for reducing energy use and engaging in pro-environmental behaviors [2]. Of the energy used by residence halls on average U.S. campuses, half of it can be attributed directly to students' behaviors [3,4]. In addition, students are likely to be receptive to behavior change messages. For example, compared to older adults in non-classroom settings, students in an educational environment respond more positively to interventions and are more likely to change their behaviors [5]. Finally, with many students living away from home for the first time in their lives, their habits and behaviors are developing in new environments and could form foundations for their future lifestyles [6].

Forming student eco-representatives ("eco-reps") has increased in popularity on U.S. college campuses as a way for peers to spread information and change environmental attitudes and behaviors ([7], see [8] for a list of American schools with such programs). Available data suggest success rates ranging from $1 \%$ reduction in energy consumption (University of Vermont) [9] to 5\% (Vanderbilt University) [10] to 13\% (University of New Hampshire) [7]. Typically, training of eco-reps involves teaching students about environmental issues and then giving them some tools to influence others. These programs often incorporate motivational elements such as competitions or economic incentives, although these alone may not always produce lasting attitude or behavior change $[11,12]$. For one, college students typically receive a flat rate living expense rather than individual electric bills, which may decrease awareness about the amount of energy consumed and remove economic motivations for altering behavior. Additionally, motivations based on economic incentives are less likely to change pro-environmental attitudes, which then limit the duration and generalizability of pro-environmental behaviors [12]. One alternative is to use social interventions such as spreading behavior and attitude change among peers.

The current theory-guided behavioral intervention program aimed to change the behavior of college students living on campus in a pro-environmental direction. Eco-reps were first trained to change their own behavior using proactive coping techniques and then given tools for communicating behavior change strategies among their peers. We theorized that by learning effective strategies to change their own behavior, eco-reps would be more effective in promoting behavior change by way of enhanced knowledge about barriers to changing anti-environmental habits. Moreover, firsthand experience with changing their own behaviors might make eco-reps better role models and the messages they spread more authentic because they can be more empathic toward others' efforts to change behaviors and more able to communicate practical advice.

\subsection{Overcoming Barriers to Environmental Behavior Change}

Proactive coping is one strategy which may aid the adoption of pro-environmental behaviors. The proactive coping process involves anticipating or preparing for a stressful event before it occurs, in 
order to thwart or minimize its effect [13]. Proactive coping can include preparing oneself to increase quality of life and personal well-being [14] and meet personal goals [15]. Thus, anticipated events are not necessarily major life stressors, but can also include threats to one's ability to meet behavioral change goals. In an environmental context, stress could be found in making the decision to change one's lifestyle and then cope with continual barriers to this change (e.g., negotiating with roommates or family over choices). Techniques to increase proactive coping skills have been effectively applied in interventions to help people manage diabetes [16], increase physical activity [17] and prepare for aging [18], for example. These actions can prepare one for many types of possible situations rather than addressing one problem or scenario. In the case of pro-environmental behaviors, proactive coping could be used to anticipate and address daily situations that may interfere with a desired behavior, such as taking the stairs when peers prefer to take the elevator.

Aspinwall and Taylor identified five stages in the proactive coping process which we incorporated into the current proposed intervention: resource accumulation, attention-recognition, initial appraisal, preliminary coping, and elicitation and use of feedback [13]. Eco-rep programs should accumulate resources by planning, organizing, and structuring meetings and providing information about pertinent behaviors to change. Mental simulation of situations one might encounter when trying to change environmentally-relevant behaviors can help eco-reps attend to and recognize the possibility of potentially difficult situations or circumstances that might interfere with their goals. Once potential barriers are recognized, reps can also use the mental simulation to initially appraise the situation by evaluating the barrier, how it may change over time, whether one should be worried about or prepare for it, and what resources they might have to cope with the barrier. Eco-reps can take preliminary coping efforts with the barriers by trying one or two new behaviors each week. Finally, there can be several steps implemented into environmental intervention programming in order for reps to elicit and use feedback about potential barriers and facilitators. This may include a group discussion in which members are encouraged to review and share difficulties or successes with behavior change during subsequent weeks' meetings. In this way, members may re-appraise the difficulty or situation surrounding the behavior change and plan barriers and facilitators based on successful behavior change strategies of others in the team.

It is important to acknowledge that applying proactive coping to environmental domains raises unique challenges. First, the necessity of behavior change may not be as obvious for pro-environmental behaviors as it is for behaviors which help to diminish the effects of illness or disease. Environmental problems and the benefits for change are often spatially and temporally distant $[19,20]$, whereas health threats are often perceptually close and personal. Second, pro-environmental behaviors may be controversial when they are seen as threatening cultural ideals such as consumerism or capitalism, e.g., see [21] or when they are not supported by particular others such as those who deny the impact of humans on climate change, e.g., [22,23]. Thus, the motivation to change one's personal behaviors may be an additional barrier compared to other behaviors that have used pro-active coping as a means of achieving personal behavioral change. 


\subsection{Spreading Pro-Environmental Behavior Change}

A variety of research within and outside of psychology indicates that messages are more likely to be effective and adopted when those spreading the information are seen as experts, e.g., [24] or opinion leaders, e.g., [25], and eco-rep programs generally acknowledge the power of peer-to-peer education [26]. However, research has not, to our knowledge, experimentally tested the effectiveness of training eco-reps to be experts about behavior change on influencing pro-environmental behavior change in others. We tested whether students trained to be experts in pro-environmental behavior change could improve the effectiveness of residence hall competitions to reduce energy use. Competitions between residence halls are a common strategy for effecting pro-environmental behavior change over a short period of time, e.g., see [27], particularly when continuous energy feedback is provided [28,29]. However, the effectiveness of competitions is often not efficiently reported and is quite variable [10]. Further, several energy competitions at the present university, when used alone, did not effectively reduce energy [4]. Thus, we aimed to benefit the current energy reduction program with a theory-guided training program using eco-reps as behavior change ambassadors and experts.

\subsection{Present Research}

The following intervention program was carried out among 15 first-year student residence halls on a large, public university campus. Eco-reps met for four weeks at the beginning of their fall semester in their first year of college, where they focused on changing their own environmental behaviors. Consistent with Community Based Social Marketing recommendations [30], we focused on pro-environmental behaviors that could be easily accomplished by a first-year college student population living in campus residence halls while still maintaining a high environmental benefit. Thus, we also obtained information about barriers and facilitators for specific behaviors and difficulty with behavior changes, which could potentially be useful to share with other college students. Students then utilized their expertise in barriers and facilitators to pro-environmental behavior change in spreading behavior change messages among their residence hall peers during a two week energy reduction competition.

We also collected data to evaluate the success of the intervention. In order to evaluate the proactive coping portion of the program, we tested whether members could successfully meet the behavior change goals implemented by the end of the eco-rep training program, and whether they could maintain behavior goals over six months after the conclusion of the intervention program. We also tested whether the eco-rep training facilitated their peers' pro-environmental behavior change and reduced energy consumption in the residence halls where they lived compared to residence halls who did not have trained eco-reps present.

\section{Method}

\subsection{Participants}

Twenty-nine students (16 women, 13 men) living within eight residence halls on campus were selected to be eco-reps. Reps were hired to work two hours a week at minimum wage during the 
training and during the residence hall competition. For the six-month follow-up survey, 24 out of the 29 original eco-team members responded via email ( $83 \%$ response rate).

Each residence hall with eco-reps had a range of 239-344 students living in the hall $(N=2147)$. All residents were first-year college students. Seven eco-rep halls were compared to eight halls without eco-reps (two additional halls were tested, one from the eco-rep group [with three eco-reps] and one from the control, but because of errors in meter readings, they were dropped from analyses). Eco-rep halls had a range of 2-7 eco-reps per hall $(M=3.71$ eco-reps per hall). The control group halls were matched to have a similar range of students per hall (250-318) and were composed of only first-year students $(N=2277)$.

Approximately $20 \%$ of residents $(n=991)$ from eco-rep and non-eco-rep halls were randomly selected to complete a follow-up online survey after the energy competition. There was a $30 \%$ response rate ( $n=293$ residents).

\subsection{Procedure}

\subsubsection{Proactive Coping Training}

Participants met once a week for four weeks during the second month of the fall semester. Each meeting was led by one researcher and one assistant, consisted of 8-10 eco-reps, and lasted approximately 2 hours. The first three meetings used the same two-part structure: first, information was provided about an environmental topic; and second, eco-team members focused on changing specific behaviors by applying the proactive coping process. During weeks two through four, team members also reported their successes and difficulties with past behaviors and revisited the proactive coping process for each behavior. See Table 1 for a breakdown of activities and behaviors introduced during each meeting. The behaviors selected were those related to energy use in the residence hall and those that students had control over. Goals for energy reduction were chosen by the researchers based on amount of energy saved $v s$. relative ease of meeting the behavioral goal. We chose to give a goal of concrete time rather than percentage of time for electronics because we assumed that students would need to use computers for school work and did not want percentages to affect their ability to use electronics for this reason. Ninety minute reductions were based on preliminary data that suggested that most students spend more than 90 minutes per day using electronics for entertainment purposes. Students were introduced to the goal, asked to calculate what they would have to do to reach the goal (e.g., if a person normally took a 10-minute shower, the new shower goal would be set for 8 minutes), and rate how difficult they thought it might be to accomplish this goal over the upcoming week.

The researchers then led members through the proactive coping process. Members were asked to close their eyes and imagine their normal daily routine which involved the specific behavior, and to assess whether there would be situations in which it would be difficult to not carry out the desired behavioral change and meet the specified goal. They were then asked to imagine things that would help them meet their goal and things that would make it hard to meet their goal and to write down the barriers and facilitators they imagined. Then they shared their barriers and ways to overcome them with the group, allowing other reps to help come up with solutions to meeting the goal. Members then took another minute with their eyes closed using mental simulation to picture putting their solutions 
into action and wrote down a take-home plan. The procedure was repeated for each behavior introduced during the meeting. Please refer to Table 2 for a sampling of the barriers and facilitators obtained during these sessions.

Table 1. Procedure for Meetings Broken Down by Behavior and Activities.

\begin{tabular}{|c|c|c|}
\hline \multirow[b]{2}{*}{ Targeted Behavior by Week } & \multicolumn{2}{|l|}{ Activity During Meetings } \\
\hline & Engagement Activities & Proactive Coping Goals \\
\hline Week 1: Hot Water Usage & $\begin{array}{l}\text { - General environmental info } \\
\text { - Personal issue } \\
\text { - Most impactful behaviors } \\
\end{array}$ & $\begin{array}{l}\text { - Take } 20 \% \text { shorter showers } \\
\text { - All laundry using cold water }\end{array}$ \\
\hline Week 2: General Electricity & $\begin{array}{l}\text { - Impacts of climate change } \\
\text { - Emotional connection to } \\
\text { climate change }\end{array}$ & $\begin{array}{l}\text { - Take the elevator } 50 \% \text { less } \\
\text { - Use lights } 25 \% \text { less }\end{array}$ \\
\hline $\begin{array}{l}\text { Week 3: Entertainment } \\
\text { Electronics }\end{array}$ & - Interconnected systems & $\begin{array}{l}\text { - Reduce usage of electronic } \\
\text { entertainment (e.g., TV, } \\
\text { computer) by } 90 \text { minutes/ day }\end{array}$ \\
\hline $\begin{array}{l}\text { Week 4: Behavior Maintenance \& } \\
\text { Communication with Others }\end{array}$ & $\begin{array}{l}\text { - Importance of continuing } \\
\text { behaviors } \\
\text { - Coping with interpersonal } \\
\text { communication } \\
\end{array}$ & $\begin{array}{l}\text { - Continue to do all behaviors } \\
\text { - Convince others to change } \\
\text { behavior }\end{array}$ \\
\hline
\end{tabular}

Table 2. Example Barriers and Facilitators.

\begin{tabular}{|c|c|c|}
\hline \multirow[b]{2}{*}{ Behavior Type } & \multicolumn{2}{|c|}{ Barriers and Facilitators Identified during Proactive Coping } \\
\hline & Barrier & Facilitators/Ways to Overcome \\
\hline General & $\begin{array}{l}\text { - Habits } \\
\text { - Forget } \\
\text { - Lose Enthusiasm }\end{array}$ & $\begin{array}{l}\text { - Alter aspects of routine slowly (e.g., change TV } \\
\text { habits for Monday then rest of week) } \\
\text { - Put reminder notes by site of behavior (e.g., note } \\
\text { on wall pointing to stairs instead of elevator) } \\
\text { - Create a list of the reasons and motivations to } \\
\text { engage in behavior change }\end{array}$ \\
\hline Take Shorter Showers & $\begin{array}{l}\text { - Lose track of time } \\
\text { - Enjoyable }\end{array}$ & $\begin{array}{l}\text { - Use stop watch to time yourself } \\
\text { - Listen to two songs on the radio and then get out } \\
\text { - Schedule showers around activities so your time } \\
\text { in shower is limited }\end{array}$ \\
\hline Cold Water Laundry & $\begin{array}{l}\text { - Belief that hot } \\
\text { water is better } \\
\text { - Stains }\end{array}$ & $\begin{array}{l}\text { - Learn that cold water is better for clothes and } \\
\text { that detergent matters more than water } \\
\text { - Wash one load in cold and one in warm and see } \\
\text { if there is a difference (there will not be any!) } \\
\text { - Pre-treat stains } \\
\text { - Hand wash stained areas before washing }\end{array}$ \\
\hline
\end{tabular}


Table 2. Cont.

\begin{tabular}{|c|c|c|}
\hline \multirow[b]{2}{*}{ Behavior Type } & \multicolumn{2}{|c|}{ Barriers and Facilitators Identified during Proactive Coping } \\
\hline & Barrier & Facilitators/Ways to Overcome \\
\hline Take Elevator Less & $\begin{array}{l}\text { - Live high up } \\
\text { - Running late } \\
\text { - Friends } \\
\text { - Too hard }\end{array}$ & $\begin{array}{l}\text { - Take the stairs down and the elevator up } \\
\text { - Learn that taking the stairs is often faster than } \\
\text { waiting for the elevator } \\
\text { - Ask them to take the stairs with you } \\
\text { - Walk to the stairs while in the middle of talking } \\
\text { as they may follow you } \\
\text { - Think of it as good exercise }\end{array}$ \\
\hline Use Less Lights & $\begin{array}{l}\text { - Working late } \\
\text { - Roommates use } \\
\text { more }\end{array}$ & $\begin{array}{l}\text { - Use focused lights (e.g., a lamp) rather than an } \\
\text { overhead light or study in a public area } \\
\text { - Try to schedule to do work during the daytime } \\
\text { - Discuss and find a compromise } \\
\text { - Leave reminders for them to shut off lights }\end{array}$ \\
\hline $\begin{array}{l}\text { Use Less Elec. } \\
\text { Entertainment }\end{array}$ & $\begin{array}{l}\text { - Boredom } \\
\text { - Enjoyable / } \\
\text { staying caught up }\end{array}$ & $\begin{array}{l}\text { - Find other activities that do not need electricity } \\
\text { (e.g., play board games instead of video games) } \\
\text { - Read or exercise during free time } \\
\text { - Try watching them on computer which generally } \\
\text { uses less electricity or watch in groups }\end{array}$ \\
\hline
\end{tabular}

In weeks two, three, and four, after part one of the meetings but before the introduction of new behaviors, behaviors from the previous weeks were reviewed in order for members to gain more behavioral feedback. Members first privately recorded the goal that they were attempting to meet and how they had performed the behavior over the past week, then asked how difficult it was to work towards their goal. Eco-reps then shared particular barriers or facilitators they came across with the group. Eco-reps were instructed to focus only on changing their own behavior during the training weeks and delay their attempts to influence others until the beginning of the competition period.

During week four, eco-reps prepared for their role in the energy competition. Using the same proactive coping theory that grounded their own behavior change, reps were asked to identify peers that they could approach and encourage to participate in energy reduction, and to identify barriers and facilitators of approaching these individuals. In order to try initial coping strategies and to elicit and use feedback, eco-reps role-played various types of interactions they might encounter. They were also provided with a handbook summarizing climate change information, the amount of energy saved by doing pro-environmental behaviors, the barriers and facilitators they identified during their training, behaviors the university recommended changing, and ten general tips for approaching others.

\subsubsection{Residence Hall Competition}

Students in all the residence halls on campus were informed that a competition was taking place to see which hall could reduce the most amount of energy. Students were told that the winning hall would be recognized in an article in the university newspaper. As the competition progressed, energy use was posted every day near the cafeteria announcing each hall's daily energy consumption, the amount they had changed from the day before, and which halls were leading the competition. During the two-week 
competition period, eco-reps filled out daily diaries online describing who they talked to, the type of interaction they had, and the types of pro-environmental behavior they targeted.

\subsubsection{Post-Competition Follow-up}

After the two-week competition period, a random sample of residents from both the eco-rep and control group halls was contacted via email to fill out a post-competition survey online. Finally, eco-reps were contacted again via email six months after the conclusion of the intervention to obtain measures of behavior maintenance on each of the behavior goals targeted during the intervention and for how many months they maintained the goal following the program.

\subsection{Measures}

\subsubsection{Anticipated and Experienced Difficulty}

Difficulty of meeting each behavioral goal during the training was measured by asking eco-reps "How difficult do you think it will be to [meet goal]?" and "How hard was it to [meet goal]?" Follow-up responses to difficulty ratings were taken at each subsequent meeting following the attempted behavior change. Reponses were recorded using a 0 (Not at All) to 3 (Very Difficult) scale.

\subsubsection{Behavioral Goals and Achievement}

Self-reported behavior change was assessed during the training by asking eco-reps about the frequency of the targeted behaviors. Specifically, they were asked, over the previous week, to indicate: (1) How long (in minutes) on average did you let the water run while taking a shower; (2) How many loads of laundry did you do in the (a) whites/hot water setting, (b) permanent press/warm water setting, (c) colors/cold water setting, and (d) delicates/cold water setting; (3) How many hours and minutes per day did you leave (a) overhead lights and, and (b) floor lamps or desk lights on in your room (even when you were not there); (4) How many times on average per day did you take the (a) elevator, and (b) stairs; and (5) How many hours and minutes per day on average did you (a) have your computer on to work, (b) have your computer on for entertainment, (c) have your computer on when you were not using it, (d) have your TV on while you watched television, (e) have your TV on when you were not watching it, and (e) have your TV on to play video games.

\subsubsection{Competition Survey}

First, eco-reps reported who they talked to, how frequently, and for how long. They were also asked to indicate whether or not they tried to motivate residents, and whether they talked about specific pro-environmental behaviors, general information about energy use, or environmental issues. The type of conversations were submitted to a principle axis factor analysis with a promax rotation and formed two unrelated factors $(r(7)=0.45, p>0.30)$ : behavior-specific messages $(\alpha=0.96)$ and general environmental messages $(\alpha=0.93)$. 


\subsubsection{Post-Competition Survey}

Residents were asked if they learned about the residence hall competition from any of the following people: (1) an eco-rep, (2) a friend, and (3) other people in their hall. Second, we asked residents whether they changed their behavior during the residence hall competition $(1=$ Did not change behavior, 2 = Changed one behavior one time, 3 = Changed one behavior for part of the competition period, $4=$ Changed one behavior for the whole competition period, $5=$ Changed more than one behavior one time each, 6 = Changed more than one behavior for part of the competition period, 7 = Changed more than one behavior for the whole competition period). Responses on this question yielded two types of related measures for frequency and number of behavior change: how many behaviors the resident changed (none, one behavior, or more than one), and how often the resident changed their behaviors (not at all, once, for part of the competition period, or for the whole competition period). Third, residents were asked if they were encouraged to change their behavior by an eco-rep using a 1 (Not at All) to 5 (Very Much) scale. Finally, residents were asked if they tried to convince others to engage in the competition using a 1 (Not at All) to 4 (Very Much) scale. In addition to the post-competition survey, the number of kilowatt hours used in the residence hall was measured for two weeks after the competition period.

\subsubsection{Six-Month Follow-up Survey}

The six month follow-up survey assessed the eco-reps' current pro-environmental behaviors with the same questions used to assess their behaviors during the training and a subjective rating of their efforts to continue to meet their goals ( $1=$ Not well at all to $5=$ Very well scale). To evaluate the length of behavior maintenance, members were asked to check a box for each month that they continued to meet each of the five goals, ranging from "did not maintain goal after training", "the last two weeks of October", and "November" through "April".

\section{Results}

\subsection{Training Process}

Anticipated and Experienced Behavior Difficulty

We used a 5 (type of behavior) $\times 2$ (time: anticipated prior to training vs. experienced during the first week post-training for a specific behavior) repeated measures general linear model to test whether behaviors differed from each other in anticipated to experienced difficulty, and to compare anticipated to experienced difficulty during the first week after they attempted the behavior change. There was a main effect for type of behavior, $F(4,52)=9.33, p<0.001, \eta_{p}{ }^{2}=0.42$, such that turning of lights $(M=2.07, S D=0.20)$ and reducing personal electricity $(M=1.96, S D=0.21)$ were considered to be significantly more difficult than reducing showers $(M=1.32, S D=0.15)$. Reducing elevator use $(M=1.54, S D=0.26)$ fell between these two extremes and was not significantly different from either. However, laundry cold water use $(M=0.59, S D=0.20)$ was considered to be significantly easier than any of the other behaviors. 
There was also a main effect of time on perceived behavioral difficulty, $F(1,13)=10.02, p<0.01$, $\eta_{p}{ }^{2}=.44$, such that behaviors were anticipated to be significantly more difficult before trying the behavior $(M=1.62, S D=0.10)$ than their experienced difficulty during the first week they were attempted $(M=1.37, S D=0.14)$. However, there was no significant interaction between time and type of behavior. The same pattern of results occurred for changes in anticipated and experienced difficulty over the course of the intervention, such that there was a main effect for behaviors, $F(1,12)=7.41$, $p<0.05, \eta_{p}{ }^{2}=0.38$, and time, $F(4,48)=14.75, p<0.001, \eta_{p}{ }^{2}=.42$, but no interaction. The pattern in mean differences in behaviors was also the same.

\subsection{Eco-Rep Behavioral Outcomes}

\subsubsection{Behavioral Goal Attainment}

We used repeated measures general linear models for each behavior to test whether eco-reps met each behavioral goal over the course of the training. Results indicate that all reported behaviors were significantly changed in a pro-environmental direction, and four of the five behavioral goals were successfully met. Specifically, minutes spent in the shower were reduced from before the training $(M=12.24, S D=4.25)$ to the end of the training $(M=7.55, S D=2.61), F(3,69)=28.74, p<0.001$, $\eta_{p}{ }^{2}=.56$ (goal was a $20 \%$ reduction, actual reductions were $37 \%$ ). Percentage of cold water loads of laundry increased from before the training $(M=51.6 \%, S D=.40)$ to the end of the training $(M=100 \%, S D=0.00), F(3,66)=29.57, p<0.001, \eta_{p}{ }^{2}=0.57$ (goal was $\left.100 \%\right)$. Number of times taking the elevator per day was reduced from before the training $(M=5.33, S D=3.18)$ to the end of the training $(M=3.57, S D=2.78), F(2,50)=16.23, p<0.001, \eta_{p}{ }^{2}=0.39$ (goal was $50 \%$ reduction, actual reductions were $36 \%$ ). Hours lights were used per day (multiplied by number of lights used) decreased from before the training $(M=8.92, S D=4.37)$ to the end of the training $(M=5.27, S D=4.38)$, $F(2,48)=3.57, p<0.05, \eta_{p}{ }^{2}=.13$ (goal was a $25 \%$ reduction, actual reductions were $37 \%$ ). Hours of using electronic entertainment per day decreased from before the training $(M=9.40, S D=4.35)$ to the end of the training $(M=6.25, S D=2.63), F(1,22)=13.61, p<0.01, \eta_{p}{ }^{2}=0.38$ (goal was a 1.5 hour reduction, actual reductions were 2.84 hours). A Grubb's test for outliers indicated that there were two members who used substantially more personal electricity before the training began. Removing these two outliers reduced the pre-intervention average $(M=8.13)$, but still created a significant intervention change, $F(1,20)=13.32, p<0.01, \eta_{p}{ }^{2}=0.40$, with a decrease still larger than the goal of 1.5 hours.

In addition, $82 \%$ of eco-reps met or exceeded the goal of reducing shower times by $20 \% ; 100 \%$ of eco-reps met the goal of using cold water in all loads of laundry; $39 \%$ of eco-reps met or exceeded the goal of reducing elevator use by 50\%; 61\% of eco-reps met or exceeded the goal of reducing light usage by $25 \%$; and $57 \%$ of eco-reps met or exceeded the goal of reducing electronic entertainment use by 1.5 hours. Put another way, $100 \%$ of eco-reps met one or more goal, $96 \%$ met two or more goals, $93 \%$ met three or more goals, $39 \%$ met four or more goals, and $11 \%$ met all 5 behavioral goals.

We compared behavior change of eco-reps during the four week proactive coping training to behavior change of other students who had initially expressed interest in the eco-rep training but who did not participate. Results from 50 non-eco-rep students indicated that those living in the same type of residence housing, in the same area of campus, and who were in the same year of school as the eco-reps 
did not significantly change their behaviors in a pro-environmental direction. Specifically, these first year college students were not more likely to take shorter showers, $F(1,49)=0.41, p=0.66$, use cold water settings when doing laundry, $F(1,49)=2.02, p=0.16$, take the stairs rather than the elevator, $F(1,49)=0.58, p=0.45$, turn off their lights, $F(1,49)=0.08, p=0.78$, put their computer to sleep, $F(1,49)=0.29, p=0.87$, or turn off their computer, $F(1,47)=0.93, p=0.34$, watch less TV, $F(1,49)=0.58, p=0.45$, or use their TVs less for playing video games, $F(1,49)=0.05, p=0.82$, after the completion of the eco-team program than they were before the program began.

\subsubsection{Behavior Maintenance}

We used repeated measures general linear models for each behavior to test whether eco-reps were able to maintain behavioral change over a six month time period relative to their original pre-intervention behavior and relative to the end of their week 4 training behavior (see Figure 1). Eco-reps were at least moderately successful in maintaining all behaviors except elevator use, and most successful with reducing shower time, using cold water in the laundry, and turning off lights.

Figure 1. Behavioral goal attainment and maintenance over time.

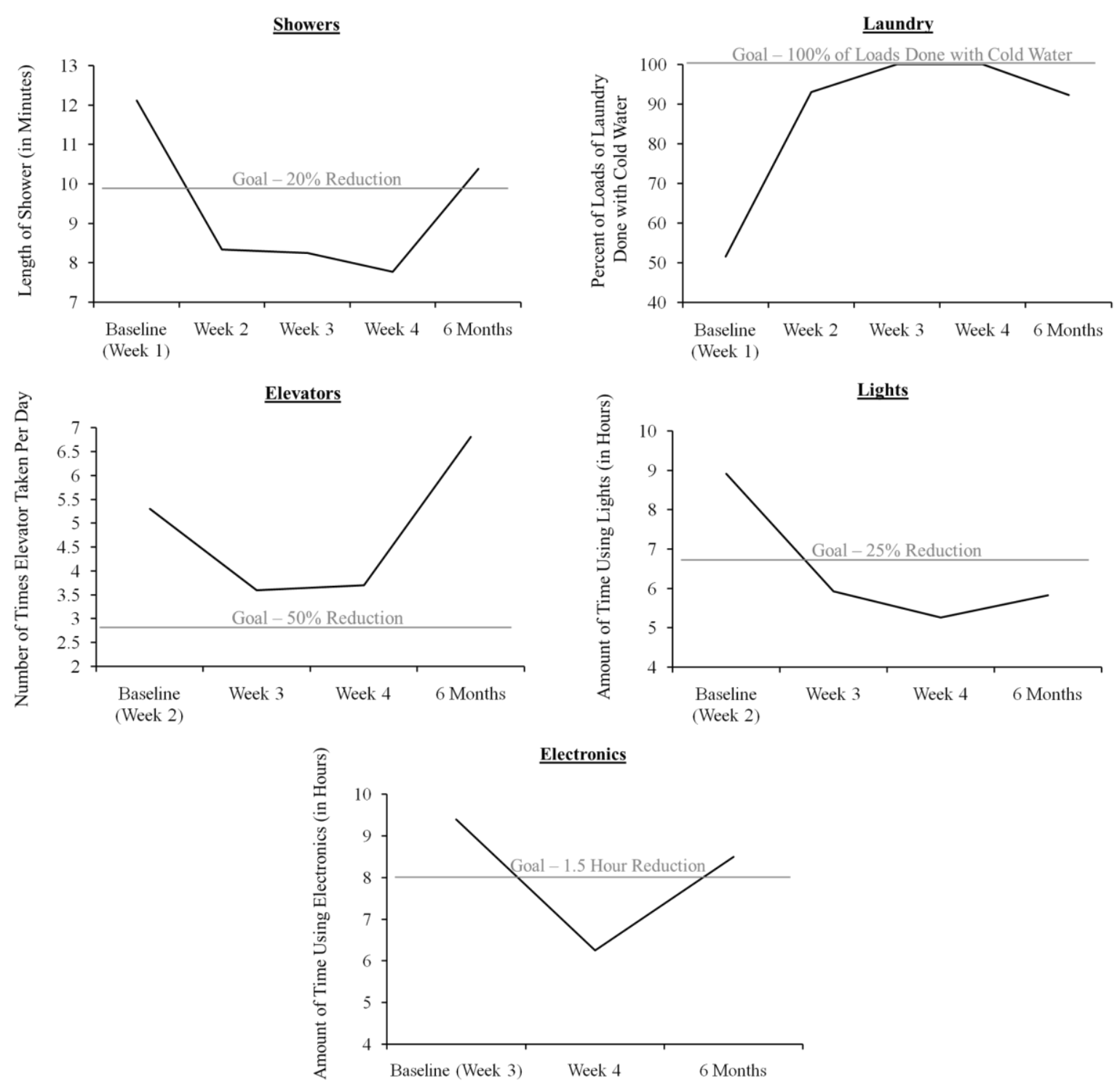


For taking shorter showers, average shower times six months later $(M=10.38, S D=5.56)$, increased from the end of training, $F(1,23)=4.83, p<0.05, \eta_{p}{ }^{2}=0.17$, but did differ marginally from their original behavior before the training, $F(1,22)=3.32, p=0.08, \eta_{p}{ }^{2}=0.13$, representing a $15 \%$ reduction from their original shower length (the behavioral goal was $20 \%$ ).

For percentage of cold water laundry loads, eco-reps reported dropping off in behavior maintenance after six months $(M=92 \%$ of loads done, $S D=0.17)$, which was a marginally significant difference from the end of the training $F(1,23)=4.07, p=0.07, \eta_{p}{ }^{2}=0.15$. However, this was still a significant change from their original behavior before the training, $F(1,21)=25.66, p<0.001, \eta_{p}{ }^{2}=0.55$, and close to the $100 \%$ goal.

For elevator use, eco-reps reported a large but statistically non-significant increase in elevator usage per day six months after the training $(M=6.81, S D=8.78)$ as compared to the last week of the training, $F(1,23)=2.48, p=0.13, \eta_{p}{ }^{2}=0.10$. This was not statistically different from their original elevator use behavior before the training began, $F(1,22)=0.25, p=0.62, \eta_{p}{ }^{2}=0.01$.

For light usage, eco-reps' reported behavior six months out $(M=5.84, S D=3.99)$ did not statistically differ from light usage at the end of the training, $F(1,20)=0.05, p=0.82, \eta_{p}{ }^{2}=0.003$. This remained a significant reduction from original behavior before the training, $F(1,19)=6.24, p<0.05$,

$\eta_{p}{ }^{2}=0.25$, and was still over the original goal of light usage reduction (i.e., light reduction six months later was $45 \%$ less than pre-intervention behavior, while the goal was $25 \%$ less).

For electronic entertainment use, eco-reps reported behavior at six months out $(M=8.50, S D=13.40)$ which was not significantly different from either the behavior at the end of the training, $F(1,21)=0.35$, $p=0.56, \eta_{p}{ }^{2}=0.02$, or the original behavior before the training, $F(1,18)=0.18, p=0.68, \eta_{p}{ }^{2}=0.01$. However, eco-reps were still meeting $66 \%$ of the original program goal (i.e., reductions six months later were over 1 hour per day, when the program goal was 1.5 hours of reduced electronics use per day).

We also analyzed the percentage of eco-reps who continued to meet each behavioral goal over the six month period: $57 \%$ of eco-reps continued to maintain or exceed the goal of reducing shower times by $20 \% ; 83 \%$ continued to maintain the goal of using cold water in all loads of laundry; $48 \%$ continued to maintain or exceed the goal of reducing elevator usage by $50 \%$; $61 \%$ continued to maintain or exceed the goal of reducing light usage by $25 \%$; and $65 \%$ continued to maintain or exceed the goal of reducing electronic entertainment use by 1.5 hours per day. Put another way, of those that responded to the six-month survey, $96 \%$ of eco-reps continued to meet one or more goal, $87 \%$ continued to meet two or more goals, $83 \%$ continued to meet three or more goals, $43 \%$ continued to meet four or more goals, and $4 \%$ ( 1 person) continued to meet all five behavioral goals.

\subsection{Residence Hall Competition}

\subsubsection{Energy Use by Hall}

We analyzed the kilowatt data using percent change as suggested by Peterson and colleagues [29]. This formula controls for baseline energy usage, with positive numbers indicating a reduction in energy usage relative to baseline, and negative numbers indicating an increase in energy usage relative to baseline. Baseline energy data was assessed while eco-reps were completing their training. Eco-reps accounted for $0.6 \%-2.0 \%$ of the residence halls' populations, meaning that their behavior alone would 
not have influenced an entire hall's baseline energy usage. The analyses were also conducted using repeated-measures ANCOVA where energy was calculated as the amount of energy used per week, per student, while controlling for baseline energy usage. A similar pattern of effects were found.

We conducted a 2 (eco-rep $v$ s. control) $\times 4$ (time: percent change during competition weeks 1 and 2 and post-competition weeks 1 and 2) mixed ANOVA. Consistent with predictions, eco-rep halls reduced their energy relative to baseline $(M=3.36 \%, S D=4.42)$ compared to control group halls which increased their energy $(M=-1.30 \%, S D=1.69), F(1,13)=7.68, p<0.02, \eta_{p}{ }^{2}=0.37$. This effect did not differ by time measured $(p>0.62)$; energy use by condition remained relatively stable across the four weeks. Importantly, as is indicated in Figure 2, eco-rep halls had a greater percent energy change during both competition and post-competition weeks than the control group halls.

This pattern of energy use represents a reduction relative to baseline of $3.1 \%-4.2 \%$ in the two competition weeks and $2.9 \%-3.3 \%$ in the two post-competition weeks for eco-rep halls. This equates to approximately 8536 kilowatt hours saved during the four competition and post-competition weeks. In contrast, for the control groups, this represents no change in energy use during the first competition week, an increase in energy usage of $2.6 \%$ for the second competition week, and $1.0 \%-1.9 \%$ for the post-competition weeks relative to baseline. This equates to an additional 2969 kilowatt hours used during the four competition and post-competition weeks. In addition, every eco-rep hall showed at least a modest decrease in energy use during the competition weeks while only one hall in the control group exhibited a reduction in energy use and five halls increased their energy use.

Figure 2. Percent change in energy use per student relative to baseline during the competition and post-competition weeks by condition.

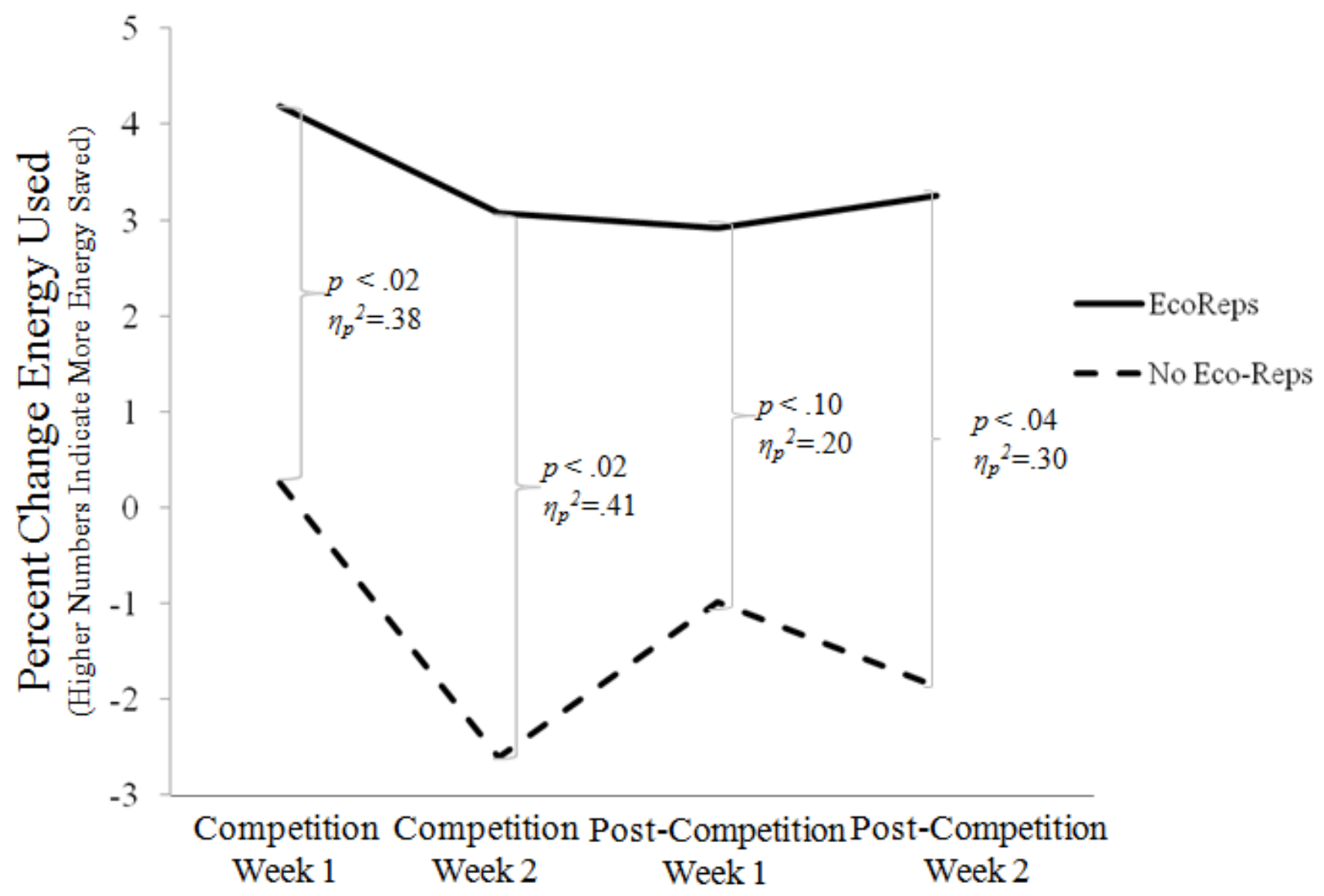




\subsubsection{Pro-Environmental Behavior Change}

Residents with eco-reps in their halls reported changing more environmentally-based behaviors $(M=2.27, S D=0.75)$ than residents in the control group halls $(M=2.04, S D=0.79), F(1,282)=6.26$, $p<0.02, \eta_{p}{ }^{2}=0.02$. These changes in behavior were correlated with change in residence hall energy use during the competition weeks $(r(14)=.59, p<0.03)$ and post-competition weeks $(r(14)=.51, p<0.06)$. Similarly, residents in halls with eco-reps reported changing their behavior more often $(M=2.80$, $S D=1.06)$ than residents in the control group halls $(M=2.50, S D=1.14), F(1,282)=5.44, p<0.02$,

$\eta_{p}{ }^{2}=0.02$. Frequency of behavior change was correlated with energy use for the competition weeks $(r(14)=0.55, p<0.04)$, but not the post-competition weeks $(r(14)=0.42, p>0.11)$.

\subsubsection{Impacts of Conversations with Eco-Reps}

Compared to the control group halls, a greater percentage of students in eco-rep halls reported learning about the competition from eco-reps $(0.7 \%$ vs. $12.8 \% ; F(1,291)=17.92, p<0.001)$, friends $(4.8 \%$ vs. $10.8 \% ; F(1,291)=3.65, p<0.06)$, and other people in the hall $(4.1 \%$ vs. $10.8 \% ; F(1,291)=4.74$, $p<0.04)$. Second, residents in eco-rep halls $(M=1.91, S D=1.26)$ reported being more encouraged by their eco-reps than residents in the control group halls $(M=1.41, S D=0.76), F(1,282)=16.53, p<0.001$.

Eco-reps' communication to residents about targeting specific behavioral change was related to reduction in energy use during the post-competition weeks $(r(6)=-0.80, p<0.04)$. In contrast, communication about environmental issues was not related to energy savings during the competition or the post-competition weeks. Compared to the control group halls $(M=1.89, S D=0.96)$, residents in eco-rep halls reported greater willingness to talk to others and try to convince them to engage in energy reduction $(M=2.23, S D=1.06), F(1,274)=7.79, p<0.007, \eta_{p}{ }^{2}=0.03$. The more conversations took place between eco-reps and residents, the more those halls reduced their energy usage during the competition $(r(6)=.85, p<0.02)$ and post-competition $(r(6)=.78, p<0.04)$ weeks. The time eco-reps spent talking to residents was not related to percent changes in energy usage during the competition or post-competition weeks.

\section{Discussion}

The study supports the use of proactive coping as a means of training eco-reps and increasing pro-environmental behavior change among college students. Eco-reps who participated in the intervention successfully increased their pro-environmental behaviors not only over the course of the training sessions but also throughout the semester following the training. Eco-reps were also effective at encouraging other students to change their behaviors. Residence halls with eco-reps reduced their overall energy use more than halls without eco-reps, and better maintained this energy reduction post-competition. Survey research supported that eco-reps successfully influenced peers' pro-environmental behavior change via encouragement and conversations about how to change specific behaviors, which was positively correlated with the actual amount of energy used in the residence halls.

The eco-rep training was not equally successful in helping team members to change all five of the different behaviors introduced, which reveals the relative difficulty of meeting and maintaining each behavioral goal within a college-residing population. Specifically, the goal of reducing elevator usage 
by up to $50 \%$ was unlikely to be met or maintained over time, perhaps because of the unique challenges to taking the stairs in an institutional setting such as building layout and social pressure. Many eco-reps lived on the 6th through 8th floors of their residence hall, making this behavior change more consistently challenging than it would be for individuals with different living situations. It is revealing that all the behaviors were perceived to be more difficult than they were actually experienced to be, suggesting that there may be fewer barriers to pro-environmental behavior change than anticipated, or that barriers to behavior change in general might be less difficult to overcome than anticipated, particularly when using proactive coping as a means for behavior change. This also suggests that without a proactive coping intervention, these behaviors may not have been attempted because of their perceived difficulty.

A 3\%-4\% drop in energy use in the residence halls with eco-reps is consistent with other successful campus interventions, e.g., [10]. Although some interventions have reported greater reductions, large percentage changes are typically reported when sophisticated feedback systems give detailed, real-time, visually appealing feedback [10]. Our program gave relatively little feedback to residents, and was still able to achieve a significant reduction in energy when this information was paired with an eco-rep training program. In addition, there may have been a greater reduction in energy use than our data revealed. We were able to measure specific kilowatt hours used in each separate residence hall, but were not able to partial-out energy that is consumed by the building itself (e.g., heating and emergency lighting which students cannot control). Thus, recorded energy reductions would have been significantly greater if we were able to examine only energy used by students. In contrast, the lack of change in energy and increased energy after the competition by non-eco-rep halls indicates that there may be unintended aspects of some university competitions, such as rebound effects, and that it is important to continue to monitor energy use after such competitions end.

\section{Limitations and Future Research}

Although the current intervention showed improved pro-environmental behavior change among eco-reps, we were limited in our ability to test whether specific elements of the proactive coping intervention were responsible for the pro-environmental behavior changes, or whether they were due to other elements of the intervention (e.g., social support and feedback, information about environmental issues, group norms). Additionally, we were unable to randomly select individuals to be eco-reps, which limits the generalizability of the training and competition findings to those who are interested in influencing others, particularly in regards to pro-environmental behavior and attitudes. Yet, this selection bias may be a natural part of recruiting and selecting individuals to be a part of an eco-rep program. Future research should evaluate whether all or some of the proactive coping components are integral to the effectiveness of such an environmental behavior change intervention and whether such programming would be effective for individuals who are not self-motivated to be eco-representatives.

As with many behavior change interventions, many of our measures relied on self-report data of personal behavior. Specifically, baseline data for the five behavioral goals was recorded based on memory and self-reflection, rather than asking members to time or record their behaviors prior to the intervention. We felt this was necessary because the knowledge that they were participating in an eco-team may have influenced reps to change baseline behavior in a pro-environmental direction. While it may 
be desirable to obtain more accurate baseline information without influencing participants, objective forms of data such as aggregate energy use within a building or home cannot differentiate between people or types of energy used. However, this may mean that the accuracy of behaviors and behavior change may not be as precise, or that members could have altered their memory for behaviors in a pro-environmental direction once participating in the program, and future studies would benefit from examining this trade-off. Yet, our ability to detect reduction in energy use among eco-rep halls gives some validity to our findings. Further, the lack of behavioral change among eco-reps not selected in the program suggests that the program was effective.

Additionally, it is important to understand whether the behaviors tested in our intervention present the same barriers or save the same amount of energy in other populations, as is encouraged by Community Based Social Marketing [30]. For example, turning off lights or reducing electronic entertainment may be easier when one lives alone as opposed to with family/roommates, and reducing elevator usage may be easier for people who do not need to climb several stories to where they live. Behaviors that we did not examine, such as energy upgrades to one's residence, can be more effective than the behaviors we examined [31], but they were not relevant for our population.

The effect of proactive coping training could possibly be improved by continuing training sessions for longer than four weeks (pending the availability of resources such as time and funding). We anticipate that after a month of weekly training sessions, meetings could be reduced to a monthly or bi-monthly frequency, focusing on proactive coping with barriers and facilitators regarding behavioral maintenance over time. Eco-reps may also benefit from revisiting other elements of the intervention as well, such as encouragement from others and information intended to increase environmental knowledge and motivation.

\section{Conclusion}

The current behavioral intervention program was successful in increasing pro-environmental behavior change in a first-year college student population. The intervention was largely successful in facilitating pro-environmental behavior change among eco-reps during the training and subsequently facilitating behavior change among eco-reps' peers during a campus energy competition. Although our ability to measure success of the program was constrained by many factors, the one month program saved over 8,500 kilowatts hours in a program directed toward only about $16 \%$ of the students living on campus. Expanding the program for longer periods of time and with more sophisticated monitoring systems could prove to be even more effective and allow greater time for behavior change to spread among students. Thus, such a program has the potential, with increased time and participants, for even greater environmental impact reduction. Information obtained about the types of barriers and facilitators students encountered when changing behaviors to be more pro-environmental and the perceived and actual difficulty of exacting behavior change goals can be used in future studies to evaluate the tradeoff between amount of energy saved and the likelihood of behavior change. Many environmental college and university programs employ eco-reps to facilitate behavior change throughout campus. Investing time and programming into successful behavior change among members may help them become more authentic role models who are aware of the challenges of specific 
behavioral changes and who can become effective agents for pro-environmental behavior changes among students across campus.

\section{Acknowledgments}

We wish to thank Aurora Lenz-Watson, Michael Sullivan, Sandra Caglia, and other members of Swim's undergraduate research lab for help with running the intervention program, data collection and entry. In addition, we wish to thank members of Penn State's Office of Physical Plant, Housing, and Residence Life staff, including Lydia Vandenbergh, John Hurst, and Dave Manos for their help and collaboration on this project.

\section{Conflict of Interest}

The authors declare no conflict of interest.

\section{References}

1. Kollmuss, A.; Agyeman, J. Mind the gap: Why do people act environmentally and what are the barriers to pro-environmental behavior? Env. Educ. Res. 2002, 8, 239-260.

2. Eagan, D.J.; Keniry, J. Green Investment, Green Return: How Practical Conservation Projects Save Millions on America's Campuses; National Wildlife Federation: Reston, VA, USA, 1998.

3. Schipper, L. Linking lifestyle and energy used: A matter of time? Annu. Rev. Energy 1989, 14, 273-320.

4. Swim, J.K. What students know about reducing energy in residence halls. 2009, unpublished data.

5. Zelezny, L.C. Educational interventions that improve environmental behaviors: A meta-analysis. J. Env. Educ. 1999, 31, 5-14.

6. Dahlstrand, U.; Biel, A. Pro-environmental habits: Propensity levels in behavioral change. J. Appl. Soc. Psych. 1997, 27, 588-601.

7. Erickson, C.; Skoglund, C. Eco-Reps programs: Conducting peer outreach in residence halls. Sustainability: The J. Rec. 2008, 1, 57-72.

8. AASHE. Association for the Advancement of Sustainability in Higher Education. Available online: http://www.aashe.org/about/ (Accessed on 7 June 2012).

9. Erickson, C. Peer to peer sustainability outreach programs: The interface of education and behavior change. Ph.D Thesis, The University of Vermont, Burlington, VT, USA, 2010.

10. Carrico, A.R.; Riemer, M. Motivating energy conservation in the workplace: An evaluation of the use of group-level feedback and peer education. J. Env. Psych. 2011, 31, 1-13.

11. Allcott, H.; Mullainathan, S. Behavioral and energy policy. Science 2010, 327, 1204-1205.

12. Kasser, T. Psychological need satisfaction, personal well-being, and ecological sustainability. Ecopsychology 2009, 1, 175-180.

13. Aspinwall, L.G.; Taylor, S.E. A stitch in time: Self regulation and proactive coping. Psych. Bull. 1997, 121, 417-436.

14. Greenglass, E.R. Proactive Coping. In Beyond Coping: Meeting Goals, Vision, and Challenges; Frydenberg, E., Ed.; Oxford University Press: London, UK, 2002; pp. 37-62. 
15. Greenglass, E.R. Proactive Coping, Resources and Burnout: Implications for Occupational Stress. In Research Companion to Organizational Health Psychology: New Horizons in Management; Antoniou, A.G., Cooper, C.L., Eds.; Edward Elgar Publishing: Northampton, MA, USA, 2005; pp. 503-515.

16. Thoolen, B.; de Ridder, D.; Bensing, J.; Gorter, K.; Rutten, G. Beyond good intentions: The development and evaluation of a proactive self management course for patients recently diagnosed with Type 2 diabetes. Health Educ. Res. 2008, 23, 53-61.

17. Stadler, G.; Oettingen, G.; Gollwitzer, P.M. Physical activity in women: Effects of a self-regulation intervention. Am. J. Prev. Med. 2009, 36, 29-34.

18. Bode, C.; de Ridder, D.T.; Bensing, J.M. Preparing for aging: Development, feasibility and preliminary results of an educational program for midlife and older based on proactive coping theory. Patient Educ. Couns. 2006, 61, 272-278.

19. Gifford, R. The dragons of inaction: Psychological barriers that limit climate change mitigation and adaptation. Am. Psychologist 2011, 66, 290-302.

20. Bloodhart, B.; Swim, J.K. Predictors, processes, and strategies for psychologically connecting with ethical consumerism messages. 2013, under review.

21. Kasser, T.; Ryan, R.M.; Couchman, C.E.; Sheldon, K.M. Materialistic values: Their causes and consequences. In Psychology and Consumer Culture: The Struggle for a Good Life in a Materialistic World; Kasser, T., Kanner, A.D., Eds.; American Psychological Association: Washington, DC, USA, 2004; pp. 11-28.

22. Feygina, I.; Jost, J.T.; Goldsmith, R.E. System justification, the denial of global warming, and the possibility of "system-sanctioned change". Pers. Soc. Psych. Bull 2010, 36, 326-338.

23. Reser, J.P.; Swim, J.K. Adapting to and coping with the threat and impacts of climate change. Am. Psychologist 2011, 66, 277-289.

24. Petty, R.E.; Cacioppo, J.T. Attitudes and Persuasion: Classic and Contemporary Approaches; W.C. Brown Co Publishers: Dubuque, IA, USA, 1981.

25. Rogers, E.M. Network Analysis and the Diffusion of Innovations, 5th ed.; Free Press: New York, NY, USA, 2003.

26. Parkin, S.; McKeganey, N. The rise and rise of peer education approaches. Drugs: Educ. Prev. Pol. 2000, 7, 293-310.

27. Dorm vs. Dorm Sustainability Competitions. Association for the Advancement of Sustainability in Higher Education. Available online: http://www2.aashe.org/competitions/ (Accessed on 7 June 2010).

28. Odom, W.; Pierce, J.; Roedl, D. Social incentive \& eco-visualization displays: Toward persuading greater change in dormitory communities. In Workshop Proceedings of Public and Situated Displays to Support Communities, OZCHI, Cairns, QLD, Australia, 2008.

29. Petersen, J.E.; Shunturov, V.; Janda, K.; Platt, G.; Weinberger, K. Dormitory residents reduce electricity consumption when exposed to real-time visual feedback and incentives. Int. J. Sustain. Educ. 2007, 8, 16-33.

30. McKenzie-Mohr, D. Promoting sustainable behavior: An introduction to community-based social marketing. J. Soc. Iss. 2000, 56, 543-554. 
31. Dietz, T.; Gardner, G.T.; Gilligan, J.; Stern, P.C.; Vandenbergh, M.P. Household actions can provide a behavioral wedge to rapidly reduce U.S. carbon emissions. Proc. Natl. Acad. Sci. USA 2009, 106, 18452-18456.

(C) 2013 by the authors; licensee MDPI, Basel, Switzerland. This article is an open access article distributed under the terms and conditions of the Creative Commons Attribution license (http://creativecommons.org/licenses/by/3.0/). 